\title{
Notas sobre a captação sonora da festa de rua em Antônia (Tata
} Amaral, 2006)

\author{
João Godoy ${ }^{\top}$
}

${ }^{1}$ João Godoy é doutor em Ciências da Comunicação na Área de Concentração de Estudo dos Meios e da Produção Mediática da Escola de Comunicações e Artes da USP. É professor da área de som do Curso Superior do Audiovisual do departamento de Cinema, Radio e Televisão da ECA- USP. Iniciou a carreira de Técnico de Som Direto em 1987 participando da captação de som de diversos curtas-metragens do chamado "Novo Cinema Paulista". Entre os trabalhos realizados destaca-se a captação do som direto dos seguintes longas-metragens de ficção: "Um céu de estrelas" (1995), "Através da janela" (1999), "Antônia" (2005), “Hoje” (2011) e "Trago comigo" (2016), todos de Tata Amaral; "Contra todos" (2002), de Roberto Moreira; "Casa de Alice" (2005), de Chico Teixeira; "Broder" (2008), de Jefferson D; "Se Deus vier que venha armado" (2012), de Luiz Dantas; "Serra pelada" (2012), de Heitor Dhalia; "O futebol" (2015), de Sergio

Oksman. 
Flagrante de um momento da filmagem de Antônia - terceiro longa-metragem da diretora Tata Amaral -, a cena batizada de festa de rua foi realizada no bairro de Brasilândia (São Paulo, SP), em março de 2005. Nessa sequência do filme, o grupo musical Antônia tem a sua primeira chance de apresentação num show que se desenrola no bairro natal das protagonistas.

Em Antônia, a principal premissa de realização definida pela direção era garantir total liberdade de ação para os atores e atrizes. Não deveria existir o habitual engessamento das ações em função das limitações impostas pelo aparato técnico do processo de realização cinematográfica, assim, a câmera e o som deveriam estar a serviço da cena. O filme buscaria criar a impressão de "um olhar que flagra eventos que estão se desenvolvendo" independentemente de uma orientação ou construção externa. Dessa forma, o desafio proposto para a equipe técnica era a criação de um método de trabalho que possibilitasse a confecção de uma obra que rompesse com a representação tradicional e, em específico para o som direto, a equação a ser resolvida era garantir o padrão de qualidade convencional "sem criar amarras" que limitassem a liberdade dos atores e das atrizes.

A sequência festa de rua sintetiza os variados desafios impostos pela proposta de realização do Antônia à captação de som direto: apresentações musicais ao vivo, diálogos e música ocorrendo simultaneamente, atuação improvisada registrada através de longos planos sequências. Além disso, para tornar mais complexa a equação do som direto, o som da apresentação musical da cena deveria realmente ser ouvido através do sistema de alto-falantes para garantir que a figuração e os atores reagissem mais intensamente estimulados pela música, realmente ouvida durante a tomada da cena. A grande dificuldade dessa opção seria a baixa inteligibilidade dos diálogos e a diminuição da 'editabilidade' dos planos de som direto, pois as vozes estariam originalmente atreladas aos trechos musicais executados durante a captação e percebidos ao fundo do registro do som direto.

Festa de rua reúne a maioria dos personagens que participam da trama de Antônia e também apresenta os principais eventos dramáticos que impulsionarão 
o desenvolvimento da narrativa. Sem dúvida, foi a sequência com a realização mais complexa em todo o filme. Além das óbvias complicações de produção, envolvidas em uma filmagem noturna exterior com mais de trezentos figurantes, a proposta da direção de filmar "ao vivo" amplificava as dificuldades e tornava o trabalho de captação do som direto um desafio. A direção apostava que a captação em tempo real das apresentações musicais no palco e das ações que aconteceriam fora dele traria maior intensidade expressiva à cena. Assim, as ações com diálogos seriam realizadas simultaneamente ao show, que estaria sendo captado ao vivo e amplificado para a plateia. A questão aparentemente insolúvel era garantir o registro inteligível dos diálogos que ocorreriam ao lado do palco com a proximidade das caixas acústicas que forneceriam intensa pressão sonora para estimular a figuração e, ao mesmo tempo, propiciar o retorno de som aos músicos durante as apresentações. Para a captação em tempo real seriam utilizadas duas câmeras, uma delas registraria prioritariamente as performances musicais, a partir de uma posição fixa frontal ao palco, e a outra acompanharia o desenrolar das ações das personagens.

Em função da complexidade da cena, o registro sonoro das apresentações musicais ficou a cargo de um estúdio móvel, especializado na captação de shows ao vivo, que utilizou em média dezoito pistas independentes para a gravação das músicas e da ambiência do show.

As condições eram totalmente desfavoráveis à captação do som direto. Para garantir, ao menos, a inteligibilidade dos diálogos, seria necessária uma relação satisfatória entre o nível de pressão sonora das vozes e o nível de pressão sonora da amplificação do palco. Assim, a estratégia para a captação do som direto da sequência envolveu primeiramente o controle do som amplificado do palco por meio dos seguintes procedimentos: o volume de saída das caixas acústicas foi muito menor do que aquele encontrado em um show real; as caixas acústicas para a plateia foram posicionadas na linha do palco, porém distantes da área onde ocorriam os diálogos; as caixas acústicas de retorno do palco foram niveladas para atuar no limiar da audição dos músicos de modo a interferirem pouco na captação do som direto, gerando algumas queixas dos músicos; além disso, a 
saída das caixas acústicas foi equalizada, amenizando a presença da música no intervalo de frequência fundamental para a compreensão da voz humana. Esses procedimentos não interferiram na qualidade do registro da música na medida em que eram realizados apenas na saída da amplificação do palco, após a captação feita pelo estúdio móvel.

A captação do som direto foi realizada por dois microfones supercardioides dinâmicos, modelo M69, fabricados pela Beyerdynamic, instalados em dois booms. Um boom operado pelo microfonista e o outro boom operado pelo técnico de som direto que carregava o gravador e os receptores de sinal de rádio no próprio corpo. Os microfones M69, originalmente desenvolvidos para serem usados no palco para a captação de vozes e instrumentos musicais de sopro, apresentam sonoridade cristalina, porém possuem baixa sensibilidade quando comparados aos direcionais condensadores normalmente empregados na captação com boom. Por isso, são costumeiramente chamados de microfones "duros", respondendo bem às altas pressões das fontes em primeiro plano e desprezando fontes com menor intensidade sonora.

A estratégia de captação apostava na baixa sensibilidade dos microfones e no controle da relação entre o nível sonoro das vozes e do nível da amplificação do palco. Assim, a eficiência dessa estratégia dependia também da intensidade das falas dos atores, que deveriam projetar as vozes como se estivessem realmente imersos em um ambiente extremamente ruidoso, numa atuação coerente com o que é visto na imagem e com o que seria ouvido posteriormente na trilha sonora mixada. Além disso, para extrair o melhor resultado da baixa sensibilidade ("dureza") do microfone escolhido, o enquadramento deveria favorecer o posicionamento do microfone o mais próximo possível da fonte sonora captada.

Os microfones operados pelos booms acompanhavam o deslocamento da câmera e captavam o som dos eventos enquadrados. Cada boom cobria uma área pré-determinada. O boom operado pelo microfonista era responsável por cobrir a região à esquerda da câmera, enviando o sinal para o gravador através de um sistema de rádio transmissão, enquanto o microfone operado pelo técnico de som cobria as ações que ocorriam ao lado direito de câmera e estava conectado 
ao gravador via cabo.

A aposta nessa arriscada estratégia revelou-se certeira, pois as vozes captadas e gravadas pelo som direto foram integralmente utilizadas na trilha sonora final. No entanto, a certeza desse acerto só pôde ser verificada muito tempo depois da captação, deixando temporariamente em suspenso se, de fato, o nosso milimétrico flagrante sonoro em festa de rua viria a ser ou não compartilhado na experiência espectatorial do filme.

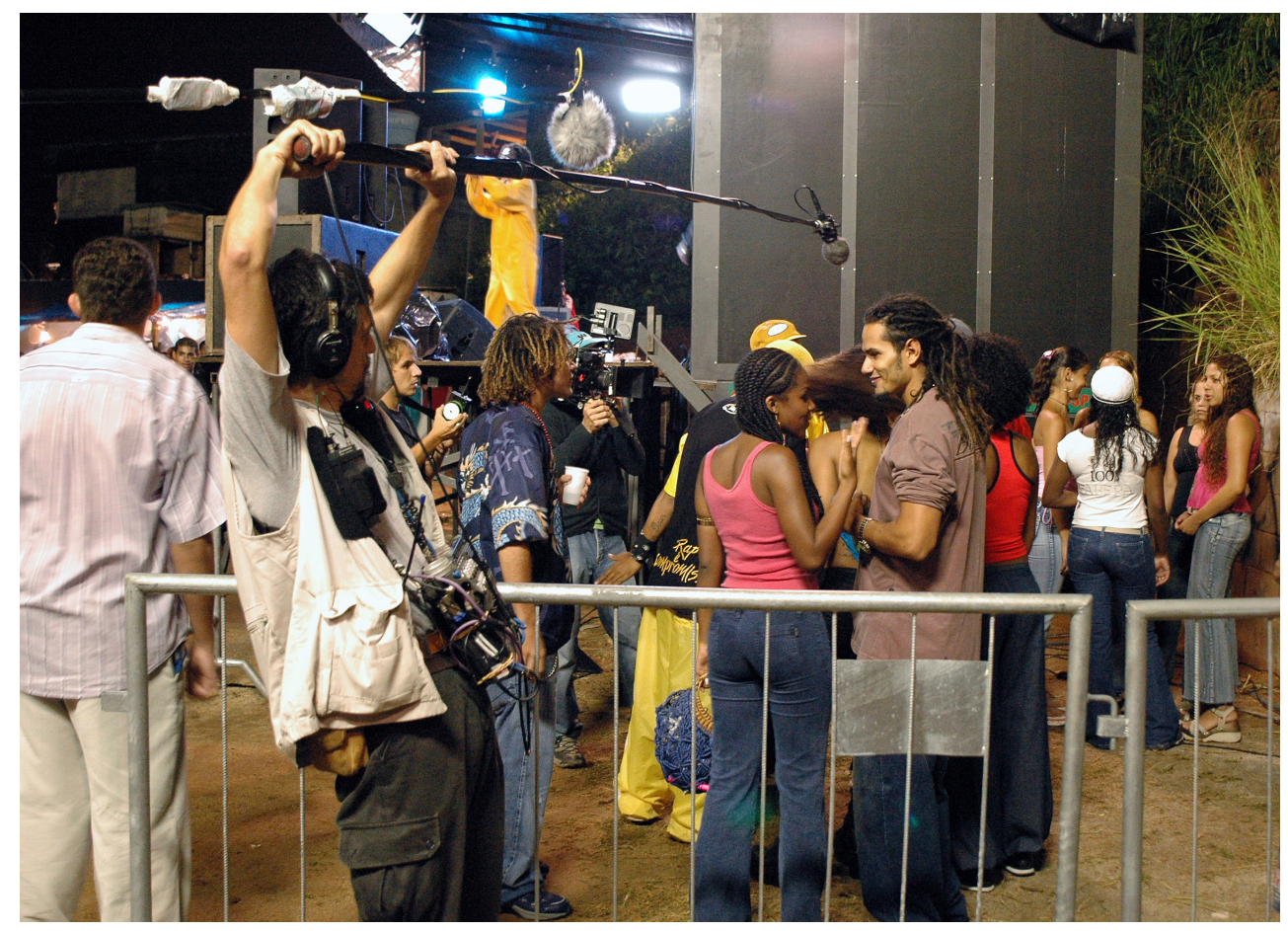

Foto: Marcelo Vigneron/divulgação Antônia. 